\title{
In vivo assessment of mitochondrial toxicity of metacavir in Rhesus monkeys after three months of intravenous administration
}

\author{
Wen ZENG ${ }^{1,3, \#}$, An-chun CHENG ${ }^{1,4, \#, *}$, Zheng-li CHEN ${ }^{1,4, \#, *}$, Qi-hui LUO ${ }^{1,4}$, Yu-bo SUN ${ }^{3}$, Zhan LI ${ }^{2}$, Feng-jun BI ${ }^{1}$ \\ ${ }^{1}$ Engineering and Technology Center for Laboratory Animals of Sichuan Agricultural University, Ya-an 625014, China; ${ }^{2}$ Nanjing \\ Chang'ao Pharmaceutical Science \& Technology Co Ltd, Nanjing 210022, China; ${ }^{3}$ Sinopharm Center for Safety Evaluation and \\ Reserch, Cheng-du 610051, China; ${ }^{4}$ Key Laboratory of Animal Disease and Human Health of Sichuan Province, Ya-an 625014, China
}

Aim: To explore the potential mitochondrial toxicities and their severities of intravenously administered metacavir, a nucleoside analog, in rhesus monkeys.

Methods: Totally 21 rhesus monkeys were randomly divided into 4 groups: metacavir $120 \mathrm{mg} / \mathrm{kg}$ group, metacavir $40 \mathrm{mg} / \mathrm{kg}$ group, zidovudine(AZT) $50 \mathrm{mg} / \mathrm{kg}$ group, and blank control group. Animals were killed after the completion of dosing or further observed in a 4-week recovery phase. Changes of structure of mitochondria in liver, kidney, skeletal muscles, and cardiac muscles were observed under transmission electron microscope(TEM). Changes of the activities of mitochondrial respiratory chain complexes and mitochondrial DNA were also determined.

Results: In metacavir $120 \mathrm{mg} / \mathrm{kg}$ group, some mitochondrial injuries were found in skeletal muscle, cardiac muscle, and liver, including that some cristae was broken and became sparse in density in the skeletal muscle, the morphology and size of mitochondria remained unchanged. Metacavir decreased the activities of respiratory chain complexes I and II and the mtDNA contents in three tissues in a dose-dependent manner; however, the extent of such decrease was lower than that in AZT $50 \mathrm{mg} / \mathrm{kg}$ group. The mitochondrial injuries in metacavir $40 \mathrm{mg} / \mathrm{kg}$ group were mild in each tissue and no obvious change in mitochondrial function was noted. On week 4 in the recovery phase, results showed that all these injuries were reversible after drug withdrawal.

Conclusion: These results suggest that metacavir has not a high risk for potential mitochondrial-related effects in rhesus monkeys.

Keywords: metacavir; rhesus monkey; toxicity; mitochondria; mtDNA; respiratory chain

Acta Pharmacologica Sinica (2009) 30: 1666-1673; doi: 10.1038/aps.2009.163; published online 16 Nov 2009

\section{Introduction}

Nucleoside analogs have currently been the first-line drugs for viral diseases such as HIV/AIDS, herpes, and viral hepatitis. Its action target is the reverse transcriptase of RNA viruses or the DNA polymerase of DNA viruses ${ }^{[1]}$. By mimicking the structure of natural nucleoside, the nucleoside analogs can competitively act in the active center of enzymes and be embedded in the synthesizing virus DNA strand, and thus terminate the extension of DNA strands and inhibit the virus replication. However, because HBV DNA polymerase is somehow similar with human DNA polymerase, these nucleoside analogs may also have an affinity for the DNA

\footnotetext{
\# These authors contribute equally to this work.

* To whom correspondence should be addressed.

E-mail zengwen10@vip.163.com; chzhli75@163.com

Received 2009-07-30 Accepted 2009-10-09
}

polymerase in host cells, resulting in potential adverse effects on the normal host tissue cells ${ }^{[2-4]}$. Data have shown that some adverse effects, including myopathies (zidovudine), neuropathies (stavudine, didanosine, and zalcitabine), fatty degeneration of the liver and lactic acidosis (didanosine, stavudine, and zidovudine), and, possibly, partial lipodystrophy (mainly stavudine), can occur after the administration of nucleoside analogs ${ }^{[3,5-8]}$. Implicated in the production of the adverse effects are interference with mitochondrial function based on abnormal morphology of muscle mitochondria, depletion of mitochondrial-encoded enzyme subunits and decreased mitochondrial gene number ${ }^{[2,5,9]}$. Nucleoside analogs associated with mitochondrial injury include the HIV nucleotide reverse transcriptase inhibitor (NRTI) zidovudine (AZT), which has been associated with mitochondrial myopathy with histological features of ragged-red fibers, and with mtDNA depletion in HIV patients ${ }^{[10-12]}$ and in rat skeletal muscle ${ }^{[13]}$, and the NRTI 
zalcitabine (ddC), didanosine (ddI) and stavudine $(\mathrm{d} 4 \mathrm{~T})^{[14-16]}$. A study of maternal-fetal exposure to AZT in patas monkeys also showed evidence for mitochondrial dysfunction including respiratory-chain defects and mtDNA reduction ${ }^{[17]}$.

Metacavir is a noval deoxyguanosine analog with a molecular formula of $\mathrm{C}_{11} \mathrm{H}_{15} \mathrm{~N}_{5} \mathrm{O}_{3}{ }^{[18]}$. Many preclinical studies have shown that it has a potential to be developed as a new antiHBV drug: in vivo and in vitro efficacy studies showed that it had good anti-HBV activity; monkey PK/PD results showed that metacavir has a high concentration in liver (or, liverenriched); our previous 6-month toxicity study showed that the main target organs of the toxic effects were gastrointestinal tract, liver, blood, and kidneys and the no-observable-adverseeffect-level (NOAEL) of metacavir in rhesus monkey was considered to be $50 \mathrm{mg} \cdot \mathrm{kg}^{-1} \cdot \mathrm{day}^{-1}$. To further explore the potential mitochondrial toxicities of long-term administration of metacavir (including the severity of toxicities and the reversibility of injuries) and provide evidences for human clinical trials, we observed the dosing results of intravenously administered metacavir in rhesus monkeys, using AZT as the positive control.

\section{Materials and methods Drugs}

Metacavir (lyophilized powder for injection, $50 \mathrm{mg}$ per vial) was provided by Nanjing Chang'ao Company (Lot No 20070412). This product is highly hydroscopic. It degrades under acidic conditions but remains relatively stable under weakly alkaline conditions. It should be stored at $4{ }^{\circ} \mathrm{C}$ in dry place.

The positive control drug is zidovudine (AZT; molecular formula $\mathrm{C}_{10} \mathrm{H}_{13} \mathrm{~N}_{5} \mathrm{O}_{4}$; molecular weight 267.25; Lot No 0701002; white powder; manufactured by Shanghai Modern Pharmaceutical Company).

\section{Equipment}

Beckman's Synchron CX4 Pro clinical chemistry analyzer, BioRad enzyme immunoassay analyzer, Hitachi H-600IV electron microscope, high speed refrigerated centrifuge (Backman, USA), constant-current-constant-voltage electrophoresis system (Bio-Rad, USA), iCycler real-time quantitative PCR detecting system (Bio-Rad, USA), and GEL EQ imaging system (BioRad, USA) were used in this experiment.

\section{Experimental animals and housing conditions}

Totally 21 healthy rhesus moneys ( 3 to 5 years of age and with body weights ranging from $3-5 \mathrm{~kg}$ at the start of dosing) were obtained from the National (Sichuan) Experimental Rhesus Monkey Resources Base (Certificate No 22). Animals were quarantined and domesticated for $30 \mathrm{~d}$ before experiment. Animal quarantine procedures included physical examinations, Mycobacterium tuberculosis tests (twice), and tests for parasites, saimonella, shigella, and B virus. Only monkeys that had passed the quarantine and met the national criteria were used for this study. Monkeys were kept under controlled conditions of temperature $\left(20-28{ }^{\circ} \mathrm{C}\right)$ and humidity $(40 \%-70 \%)$. A twelve hour day and night cycle was maintained in the animal house. Approximately $200 \mathrm{~g}$ chow was supplied to each animal (available ad libitum) on the morning, and an apple or vegetable with equal nutrients were provided around $4 \mathrm{pm}$.

\section{Experimental methods Groups and dosages}

Twenty-one rhesus monkeys were randomized into metacavir $120 \mathrm{mg} / \mathrm{kg}$ group ( 3 males and 3 females, iv), metacavir 40 $\mathrm{mg} / \mathrm{kg}$ group ( 3 males and 3 females, iv), blank control group ( 3 males and 3 females, intravenously administered with normal saline), and AZT $50 \mathrm{mg} / \mathrm{kg}$ group (2 males and 1 female, po). In metacavir groups, the dosages of $120 \mathrm{mg} / \mathrm{kg}$ and 40 $\mathrm{mg} / \mathrm{kg}$ were 72 and 45 times, respectively, of the recommended clinical dosage for human; in AZT $50 \mathrm{mg} / \mathrm{kg}$ group, the dosage was 2 times of the recommended clinical dosage for human (all based on body surface area). Drugs/placebo was given 6 times every week for consecutively three months. In the metacavir groups and blank control group, 4 animals ( 2 males and 2 females) were killed 3 months after the start of dosing, and the remaining 2 animals in each group were used for observation during the 4-week recovery phase. In AZT 50 $\mathrm{mg} / \mathrm{kg}$ group, all animals were killed 3 months after the start of dosing.

\section{Laboratory study}

The general conditions (eg changes in body weight and food consumption), body temperature, ECG parameters, hematological and biochemical parameters, bone marrow, immunotoxicities, and histopathology were observed.

Specimen collection: Autopsy was performed after animals were killed by exsanguination under phenobarbital anesthesia. The fresh tissues/organs including liver, kidney, skeletal muscle, and cardiac muscle were dissected quickly. Specimens were packed and labeled with tinfoil paper and stored at a liquid nitrogen container, and $24 \mathrm{~h}$ later transferred to a $-70{ }^{\circ} \mathrm{C}$ refrigerator. These specimens were used for extracting mitochondria and determining the activities of respiratory chain complexes and the mitochondrial DNA (mtDNA) contents. Also, some tissues were fixed in 3\% glutaraldehyde and were used for the observation of mitochondrial morphology and structure under electron microscope ${ }^{[17,19,20]}$.

Observation of the ultramicro-structure of mitochondria with transmission electron microscope (TEM): Fresh tissues (including liver, kidney, skeletal muscle, and cardiac muscle) were cut into $1 \mathrm{~mm}$ cubes, which were fixed in 3\% glutaraldehyde for $2 \mathrm{~h}$, and then fixed in 1\% osmium tetroxide, stepwise dehydrated in graded acetone, and infiltrated, embedded, and polymerized in EPON 812. The semi-thin sections were optically positioned and further sectioned with ultramicrotome into 50-60 nm pieces, which were collected on copper grids, double-stained with uranyl acetate and lead citrate, and then observed under Hitachi H-600IV transmission electron microscope and photographed.

Determination of the activities of respiratory chain complexes I-IV: We used animal tissue mitochondria isolation 
kit to isolate mitochondria, and used mitochondrial respiratory chain complex determination kit to evaluate the enzyme activities of complexes I (NADH-CoQ reductase), II (sccinateCoQ reductase), III (CoQ-cytochrome C reductase), and IV (cytochrome C oxidase) ${ }^{[17,19]}$. Also, we used animal mitochondrial protein content determination kit to determine the mitochondrial protein content in animal tissues. The activity was computed using the following formula: specimen activity=micromole respiratory chain enzyme per minute per milligram. Reagents included animal tissue mitochondria isolation kit (Lot № 4-665612-12), animal tissue mitochondria lysis kit (Lot № 1-2514-12), Genmed animal mitochondrial protein content determination kit (Lot № 6-361211-10), and animal mitochondrial respiratory chain complexes I, II, III, and IV activity quantitative determination kits (Lot No 1-350014-11, 1-250029-12, 1-423517-14, and 1-45017-10, respectively). All these reagent kits were purchased from GenMed Scientifics, Shanghai, China.

QPCR analysis of monkey mtDNA contents: using tissue total DNA extraction kit to extract tissue total DNA, and using QPCR technique to quantitatively determine mitochondrial mtDNA (Cytochrome $b$ gene) and nuclear nDNA (Actin gene) in liver, kidney, skeletal muscle, and cardiac muscle. Cytochrome $b$ /actine ratio was used to evaluate the effects of drugs/placebo on mitochondrial mtDNA contents and damages. SYBR Green RT-PCR technique was used during QPCR determination, and the reagent used was SYBR ${ }^{\circledR}$ Premix Ex Taq $^{\text {TM }}$ II (Perfect Real Time) qualification PCR reagent kit [Takara Biotechnology (Dalian) Co Ltd].

Primer design was performed based on the monkey-derived mitochondrial Cytochrome $b$ gene and nuclear Actine gene sequences in the GenBank gene database. According to the related literature ${ }^{[19]}$, the following primer sequences were designed and synthesized by Takara Biotechnology (Dalian) Co Ltd.

The upstream primer of Actin gene was: 5'-AGATCATGTTTGAGACCTTCA-3' and the downstream primer was: 5'-CGTAGCTCTTCTCCAGGGAGG-3'. The upstream primer of cyt-b gene was: 5' -CATGATACCAATACGCAAATC-3' and the downstream primer was: 5'-CGTGTGAGAGTGGGGCTGC-3'.

Taq enzyme, upstream primers, downstream primers, template, and $\mathrm{dH}_{2} \mathrm{O}$ were mixed for QPCR; the total volume of the reaction system was $25 \mu \mathrm{L}$. When making the standard curve, we used the PCR products of these two genes, determined their concentrations of nucleic acids, then made $1: 10^{5}-1: 10^{12}$ dilution with $\mathrm{dH}_{2} \mathrm{O}$ for QPCR, and finally utilized the $\mathrm{Ct}$ value in QPCR results to draw standard curve. Meanwhile, by analyzing the PCR products dissociation curves, we decided their specific differences under QPCR. During the determination of specimens, QPCR reaction system and conditions were consistent with those during standard curve drawing. By analyzing QPCR-derived Ct value and using the standard curve formula, we calculated the DNA copies in the specimens. The final result was the ratio between Cytochrome $b$ gene mean copies and Actin gene mean copies.

\section{Statistical analysis}

The measurement data including respiratory chain complex enzyme activities and $C t$ values were expressed as mean $\pm S D$. The statistical significance of intra-group difference was analyzed with ANOVA followed by Dunnett's test.

The results of morphological anatomy and histopathology were judged using qualitative indicators.

\section{Results}

Table 1 summarizes the results of the repeated dose toxicity experiment of metacavir and AZT. Compared with the baseline, the repeated dosing of metacavir mainly caused the following toxic effects: decrease in red blood cell count and haemoglobin $(\mathrm{Hb})$, compensatory increase of bone marrow erythrocyte series (accompanied by the increase of reticulocytes), damaged hepatic functions (resulting in the decrease in total protein, albumin, and glucose, positive urine occult blood, and adipose degeneration of hepatocytes), and mild necrosis and shedding of the epithelia of renal tubules. The main mito-

Table 1. Summary of the results of the repeated dose toxicity experiment of metacavir and zidovudine (AZT).

\begin{tabular}{|c|c|c|}
\hline Animal (number) & Treatment (duration) & Major treatment-related clinical observations \\
\hline $\begin{array}{l}\text { Monkey (rhesus, } \\
6 / \text { group, iv) }\end{array}$ & $\begin{array}{l}\text { Metacavir } 40 \mathrm{mg} / \mathrm{kg}(90 \mathrm{~d}) \\
\text { Metacavir } 120 \mathrm{mg} / \mathrm{kg}(90 \mathrm{~d}) \\
75 \times \text { daily dose for human } \\
(40 \mathrm{mg} / \mathrm{d})\end{array}$ & $\begin{array}{l}\text { Hematological injuries included decreases in RBC count and hemoglobin level, compensative } \\
\text { increase in bone marrow erythrocytes (accompanied by the increase of reticulocytes), damaged } \\
\text { hepatic functions (resulting in the decrease of total protein, albumin, and glucose, positive } \\
\text { urine occult blood, and adipose degeneration of hepatocytes), stimulating effects on duodenal } \\
\text { and gastric mucosa, and mild necrosis and shedding of the epithelia of renal tubules. No renal } \\
\text { toxicity was noted } 3 \text { months after the start of dosing; however, mild necrosis and exfoliation of } \\
\text { renal tubular epithelia were found } 6 \text { months after the start of dosing. All these toxic reactions } \\
\text { returns to normal } 8 \text { weeks after drug withdrawal. }\end{array}$ \\
\hline
\end{tabular}

Monkey (rhesus, AZT $50 \mathrm{mg} / \mathrm{kg}(90 \mathrm{~d})$

3/group, po) 2×human dose
The adverse reactions during dosing included: nausea, vomiting, and decrease of appetite; remarked decrease in RBC count, haemoglobin concentration, total protein, albumin, and albumin/globulin ratio; increase of total bilirubin and creatinine; and decrease of WBC and granulocytes. 
chondrial toxicity is the severe diffuse adipose degeneration of hepatocytes in the central zone of the hepatic lobule; however, clinically no adverse reactions such as myopathy, neuropathy, peripheral lipodystrophy, or pancreatitis were noted.

\section{Ultramicro-structure of mitochondria with transmission electron microscope (TEM)}

Transmission electron microscopy (TEM) was performed in the liver, kidney, skeletal muscle, and cardiac muscle 3 months after the initial dosing and during the recovery phase to observe the changes of mitochondrial structure (Figure 1-4).

Among all the four killed animals (4/4) in the blank control group, mitochondria was rich in kidney, skeletal muscle, and cardiac muscle with clear bilayer structure, dense cristae, and regular alignment; however, swollen mitochondria and mildly dilated rough endoplasmic reticulum were found in hepatocytes, which might be relevant with experimental maneuvers. Among all the killed animals (4/4) in the metacavir $120 \mathrm{mg} / \mathrm{kg}$ group, no obvious mitochondrial injuries in cardiac muscle or kidney were noted. The dosing-relevant broken cristae and sparse cristae were found in skeletal muscle cells, while their morphologies and sizes had no remarkable changes in the metacavir $120 \mathrm{mg} / \mathrm{kg}$ group. Also certain mitochondrial injuries were observed in hepatocytes, and chromatin condensation in nucleus was obvious. Results from the recovery phase showed that all these injuries were reversible after drug withdrawal. Compared with the blank control group, among
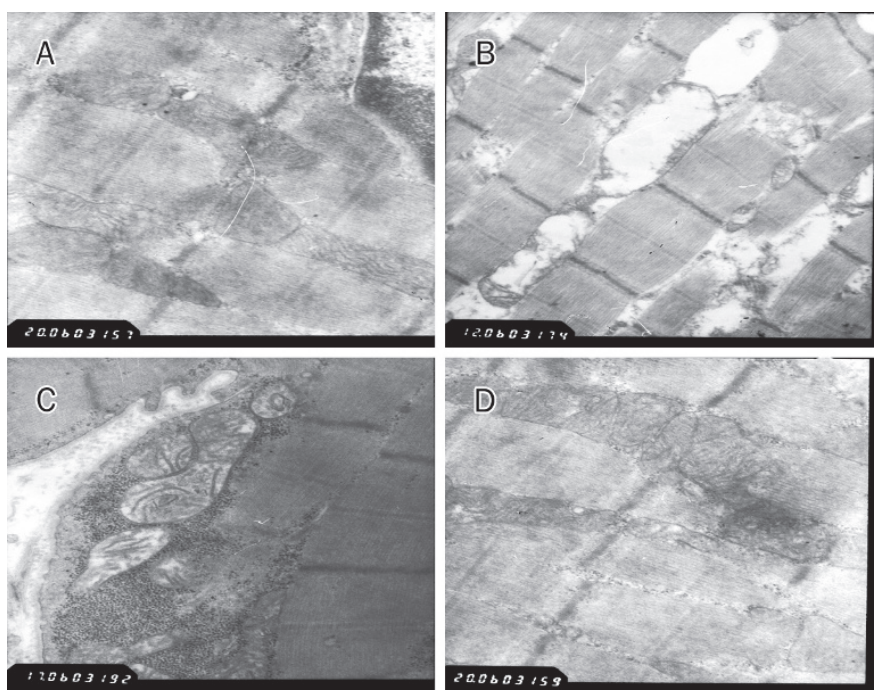

Figure 1. Micro-structure of mitochondria in skeletal muscle in rhesus monkeys. (A) in the blank control group $(\times 20000)$, the mitochondria has normal morphology and structure, and its cristae are tightly and evenly distributed; (B) in AZT $50 \mathrm{mg} / \mathrm{kg}$ group $(\times 12000)$, compared with A, the mitochondrial cristae disappeared, became swollen, and formed vacuoles. Some outer membrane disappeared, and the structure was severely damaged; (C) in metacavir $120 \mathrm{mg} / \mathrm{kg}$ group $(\times 17000)$, 3 months after the initial dosing, some mitochondrial cristae was broken, and the density became sparse, while the morphology and size remained unchanged; (D) in metacavir $120 \mathrm{mg} / \mathrm{kg}$ recovery phase $(\times 20000)$, compared with $\mathrm{A}$, the morphology and structure was normal.
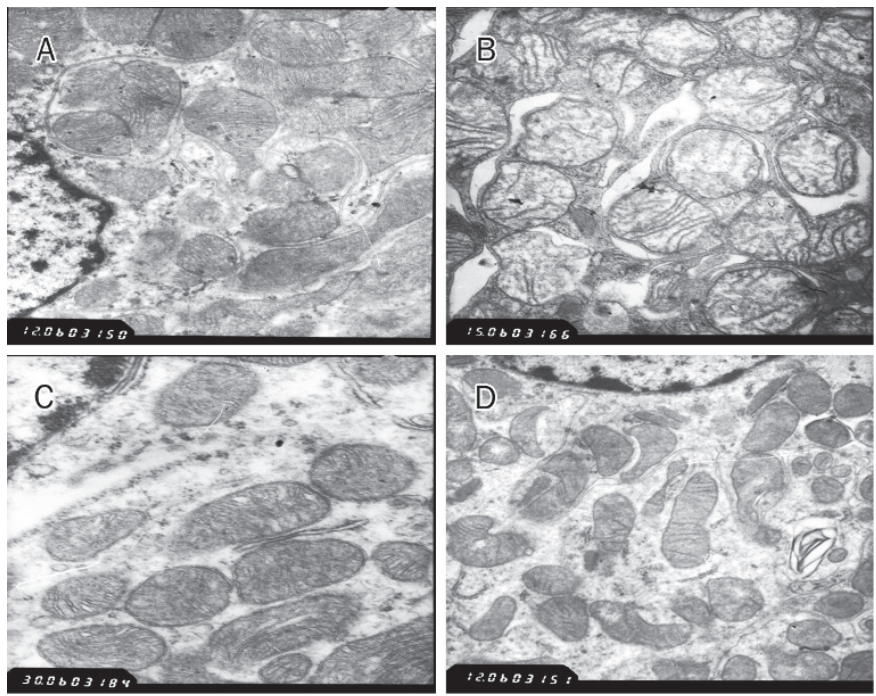

Figure 2. Micro-structure of mitochondria in kidney in rhesus monkeys 3 months after the initial dosing. (A) in blank control group $(\times 12000)$, mitochondria is rich in kidney with clear bylayer structure, dense cristae, and regular alignment; no swollen mitochondria is found. (B) in AZT $50 \mathrm{mg} / \mathrm{kg}$ group $(\times 15000)$, compared with $A$, the mitochondrial cristae are partly damaged, severely broken, or distorted; the mitochondria became mildly swollen. (C) in metacavir $120 \mathrm{mg} / \mathrm{kg}$ group ( $\times 30000)$, three months after the start of dosing, compared with $\mathrm{A}$, the morphology and structure is normal. (D) in metacavir $120 \mathrm{mg} / \mathrm{kg}$ group, during the recovery phase $(\times 12000)$, compared with A, the morphology and structure is normal.
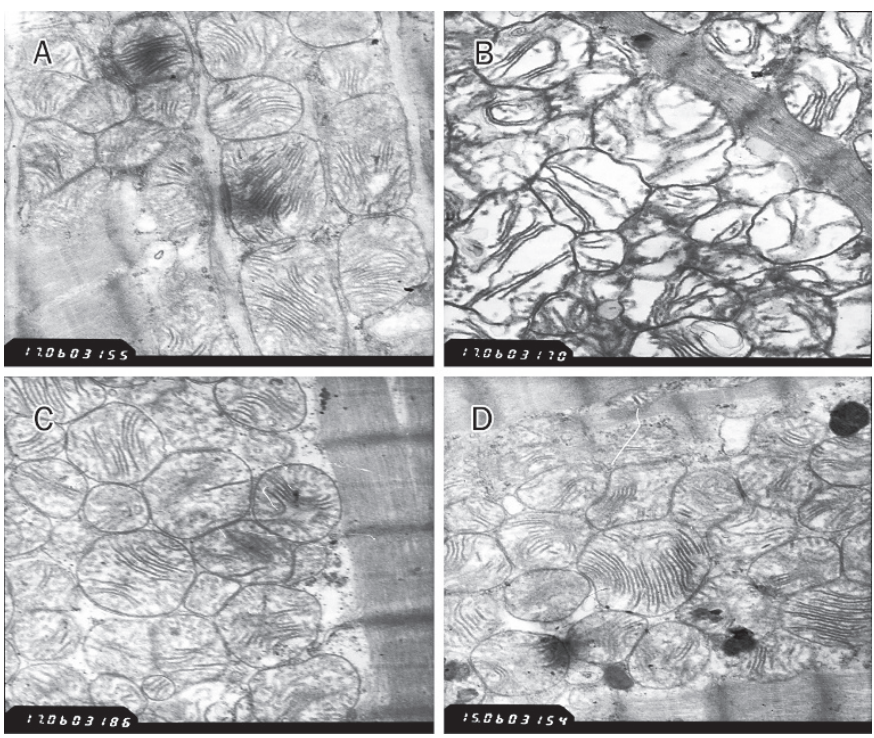

Figure 3. Micro-structure of mitochondria in cardiac muscle in rhesus monkeys. (A) in blank control group ( $\times 17000)$, mitochondria was rich in cardiac muscle with clear bylayer structure, dense cristae, and regular alignment; no swollen mitochondria was found. (B) in AZT $50 \mathrm{mg} / \mathrm{kg}$ group $(\times 17000)$, compared with $A$, the mitochondrial cristae were remarkably damaged and severely broken; the mitochondria became remarkably swollen and distorted with severely damaged structure. (C) in metacavir $120 \mathrm{mg} / \mathrm{kg}$ group ( $\times 17000$ ), three months after dosing, compared with $\mathrm{A}$, the cristae density slightly became sparse, but without obvious changes in morphology and size. (D) in metacavir $120 \mathrm{mg} / \mathrm{kg}$ recovery phase ( $\times 15000)$, compared with $A$, the morphology and structure was normal. 

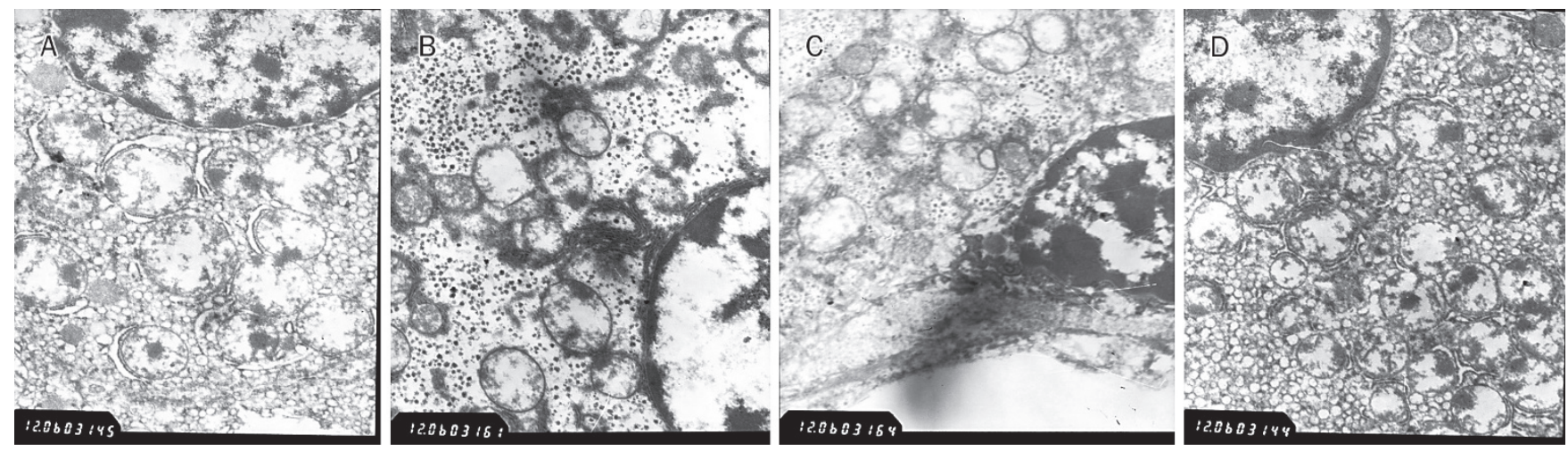

Figure 4. Micro-structure of mitochondria in liver in rhesus monkeys. (A) in blank control group ( $\times 12000)$, chromatin was evenly distributed in the nucleus of hepacytes, with clear nuclear membranes; swollen mitochondria can be seen inside cells; and rough endoplasmic reticulum was mildly dilated. (B) in AZT $50 \mathrm{mg} / \mathrm{kg}$ group (×12000), compared with A, chromatin was slightly condensated with clear nuclear membranes; intracytoplasmic mitochondria was swollen at varied extents; and the glycogen particles were rich. (C) in metacavir $120 \mathrm{mg} / \mathrm{kg}$ group $(\times 12000)$, three months after the start of dosing, in hepatytes, nuclear chromatin was slightly condensated with clear nuclear membranes; intracytoplasmic mitochondria was swollen; and some glycogen particles disappeared. (D) in metacavir $120 \mathrm{mg} / \mathrm{kg}$ recovery phase (×12000), compared with A, the morphology and structure was normal.

all the killed animals (4/4) in the metacavir $40 \mathrm{mg} / \mathrm{kg}$ group, no obvious drug-related mitochondrial injuries in skeletal muscle, cardiac muscle, kidney, or liver cells were noted. Compared with the blank control group, among all the killed animals (3/3) in AZT $50 \mathrm{mg} / \mathrm{kg}$ group, the mitochondria in liver, kidney, skeletal muscle, and cardiac muscle experienced relatively obvious injuries, although their severities varied. The main findings included: the cristae were partly damaged, severely broken, swollen or distorted; the chromatin condensation in nucleus was obvious; in some skeletal muscle cells, the mitochondrial cristae even disappeared or became swollen, forming vacuoles.

\section{Activities of respiratory chain complexes I-IV}

The activities of mitochondrial respiratory chain complexes I, II, III, and IV after the dosing of metacavir or AZT were shown in Table 2.

Compared with the blank control group, in the AZT 50 $\mathrm{mg} / \mathrm{kg}$ group, the activities of mitochondrial respiratory chain complexes I-IV in skeletal muscle and cardiac muscle were significantly decreased by up to $50 \%$ after 3 months of oral administration; the activities of respiratory chain complexes I, III, and IV (but not II) in renal tissues were significantly decreased; and the activities of respiratory chain complexes I, II, and III (but not IV) in liver tissues were significantly decreased.

In metacavir $120 \mathrm{mg} / \mathrm{kg}$ group, no remarkable effects on the activities of mitochondrial respiratory chain complexes in renal tissues were noted after 3 months of administration; however, the activities of respiratory chain complexes I and II (but not III and IV) in skeletal muscles and cardiac muscles were significantly decreased; and the activity of respiratory chain complex I (but not II, III, and IV) in liver tissues was significantly decreased. The above results suggested that metacavir $120 \mathrm{mg} / \mathrm{kg}$ did not cause mitochondrial injury in renal tissues but might cause such injuries in skeletal muscle, cardiac muscle, and liver tissues, especially in skeletal muscle. The enzyme activities increased 4 weeks after drug withdrawal, indicating these injuries were reversible.

In metacavir $40 \mathrm{mg} / \mathrm{kg}$ group, no effect on the activity of tissue enzymes was observed, especially no obvious effect on some of the mtDNA-encoded Cytochrome $c$ oxidase subunits was noted, indicating that no functional damage of mitochondria was detected.

\section{Effects on mtDNA contents}

The effects of metacavir and AZT on mtDNA contents in cardiac muscle, skeletal muscle, liver, and kidney are listed in Table 3.

As shown by QPCR technique in the quantitative determination of mtDNA (Cytochrome $b$ gene) and nuclear nDNA (Actin gene), the cytochrome $b /$ actin ratio varied among different rhesus monkeys.

After 3 months of experiment, compared with the blank control group, in AZT $50 \mathrm{mg} / \mathrm{kg}$ group, mtDNA content significantly decreased in skeletal muscle, cardiac muscle, and liver by $70 \%$ or higher $(P<0.01)$ and also significantly decreased in kidney $(P<0.05)$, suggesting the decrease of mtDNA content was correlated with the mitochondrial toxicities caused by oral administration of AZT.

In the metacavir $40 \mathrm{mg} / \mathrm{kg}$ group, the mtDNA contents in skeletal muscle, kidney, cardiac muscle, and liver were comparable with those in the blank control group $(P>0.05)$. However, in the metacavir $120 \mathrm{mg} / \mathrm{kg}$ group, the mtDNA contents significantly decreased in skeletal muscle $(P<0.05)$, and liver $(P<0.05)$, and cardiac muscle $(P<0.01)$; however, they were all higher than those in AZT $50 \mathrm{mg} / \mathrm{kg}$ group. It is believed such decrease was correlated with drug administration. In the blank control group, the Cytochrome $b$ /actin ratios were $15.21,3.69$, and 6.13 in kidneys of three monkeys, indicating that Cytochrome $b$ /actin ratio varied largely among rhesus monkeys; meanwhile, in metacavir $120 \mathrm{mg} / \mathrm{kg}$ group, the 
Table 2. Effects of 3-month administration of metacavir and zidovudine (AZT) on the activities of mitochondrial respiratory chain complexes I-IV in skeletal muscle, liver, kidney, and heart (mean \pm SD). ${ }^{b} P<0.05,{ }^{C} P<0.01$ vs control. ${ }^{e} P<0.05,{ }^{f} P<0.01$ vs AZT $50 \mathrm{mg} / \mathrm{kg}$ group.

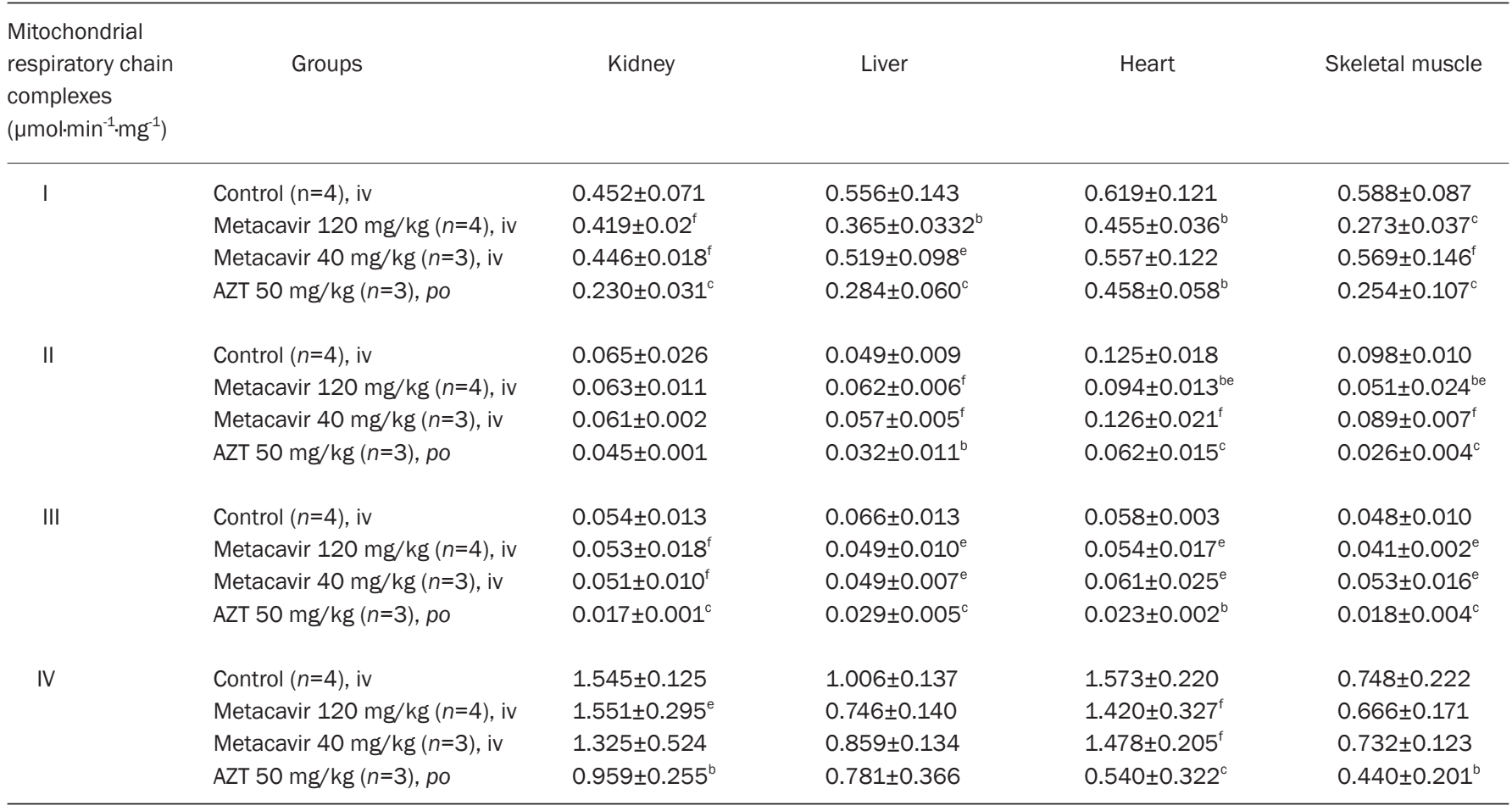

Note: $n$ : animal number.

Table 3. Effects of metacavir and zidovudine (AZT) on mtDNA contents in cardiac muscle, skeletal muscle, liver, and kidney 3 month after initial dosing. ${ }^{\mathrm{b}} P<0.05,{ }^{\mathrm{c}} \mathrm{P}<0.01$ vs control.

\begin{tabular}{|c|c|c|c|c|}
\hline & \multicolumn{4}{|c|}{ mtDNA (relative cytochrome b/actin ratio) } \\
\hline & Kidney & Liver & Cardiac muscle & Skeletal muscle \\
\hline Blank control group ( $n=3$, iv) & $8.34 \pm 6.07$ & $9.14 \pm 2.25$ & $29.00 \pm 6.48$ & $13.66 \pm 16.64$ \\
\hline Metacavir $120 \mathrm{mg} / \mathrm{kg}$ group ( $n=4$, iv) & $2.51 \pm 1.23^{b}$ & $3.63 \pm 3.94^{b}$ & $3.32 \pm 1.93^{c}$ & $2.39 \pm 2.26^{b}$ \\
\hline Metacavir $40 \mathrm{mg} / \mathrm{kg}$ group ( $n=4$, iv) & $5.14 \pm 2.71$ & $8.99 \pm 4.66$ & $35.09 \pm 27.35$ & $6.75 \pm 3.50$ \\
\hline AZT $50 \mathrm{mg} / \mathrm{kg}(n=3, p o)$ & $1.20 \pm 0.90^{b}$ & $0.96 \pm 0.38^{c}$ & $1.22 \pm 0.88^{c}$ & $0.97 \pm 0.73^{c}$ \\
\hline
\end{tabular}

Note: $n$, animal number.

Cytochrome $b$ /actin ratios slightly decreased in 2 animals and remained normal in 2 animals, indicating that metacavir $120 \mathrm{mg} / \mathrm{kg}$ had a weak effect on mtDNA in renal tissues. On week 4 in the recovery phase, the mtDNA contents in all tissues in the metacavir $120 \mathrm{mg} / \mathrm{kg}$ group showed rising trends.

\section{Discussion}

The mitochondrial toxicity of nucleoside analogs has increasingly become a research hotpot. In recent years, in vitro models including HepG2, GEM, and other cell strains were used for evaluating the effects of nucleoside analogs on the structure, function, and gene contents of mitochondria ${ }^{[2,20]}$, while in vivo studies often used woodchucks as the animal models. Few reports have used rhesus monkeys as the experimental models. However, woodchucks can carry plague and therefore are difficult to be imported into China. As a result, our study used rhesus monkeys as the sensitive animals, with an attempt to establish rhesus monkey model for mitochondrial toxicity evaluation ${ }^{[21-25]}$.

Mitochondrial toxicities are relatively tissue-specific and drug-specific. The influences of mtDNA damage on tissues depend on the reliance of different tissues on ATP. Organs with larger ATP demands tend to experience cellular changes or death when the ATP level is below certain threshold. Studies showed that, compared with mitochondrial function tests such as respiratory chain enzyme activity or lactate, mtDNA damage analysis can provide more prompt and more sensitive parameters for toxicity evaluation ${ }^{[2,20]}$. Nucleoside analogs 
may cause mitochondrial damage through interfering with mtDNA replication or through inhibiting synthesis of essential mitochondrial proteins ${ }^{[26]}$. Nucleoside analogs can inhibit the mitochondrial-specific DNA polymerase ${ }^{[27]}$ and can incorporate into replicating DNA to cause chain termination. Some animal- or HIV patients-based studies found that, when the mtDNA contents were decreased by $70 \%$ or higher, clinical symptoms of mitochondrial toxicities includeing myopathies, neuropathies, and partial lipodystrophy occurred ${ }^{[2,28]}$. Based on the above literatures, we designed the test to evaluate the Mitochondrial toxicity of Metacavir in Rhesus Monkeys after Three Months of Intravenous Administration.

In our study, QPCR showed that the normal values of mtDNA fluctuated widely among different animals, which was comparable with the results observed by Biesecher $\mathrm{G}$ et al in $2003^{[19]}$. It is important to design experiments with larger sample size to interpret the results more accurately. Compared with skeletal muscle, kidney, and liver, the cardiac muscle has the highest cytochrome b/actin ratio, which is consistent with literatures ${ }^{[17,19]}$. Mitochondrial dysfunction has been most clearly associated with $\mathrm{AZT}^{[17]}$ in both humans ${ }^{[29]}$ and in primates ${ }^{[17]}$, which is consistent with our results in this study.

In this report, we found that the hematological and biochemical parameters in the metacavir and AZT group significantly changed, and suggested that metacavir and AZT caused the toxic reactions. Meanwhile, electron microscopy of the mitochondria in different tissues showed that: structural changes and injuries at different extents occurred in the cells of cardiac muscle, skeletal muscle, kidney, and liver. For the activities of respiratory chain complexes I-IV, all results suggested that AZT $50 \mathrm{mg} / \mathrm{kg}$ caused severe mitochondrial injuries in liver, kidney, skeletal muscle, and cardiac muscle, especially in skeletal muscle and cardiac muscle, which is consistent with the TEM findings and many clinical reports on the mitochondrial myopathy caused by AZT. However, in metacavir $120 \mathrm{mg} / \mathrm{kg}$ group, the severities of these injuries were less than those caused by AZT $50 \mathrm{mg} / \mathrm{kg}$, which was consistent with the TEM findings and with the fact that mitochondrial toxicities are relatively tissue-specific and drug-specific.

In AZT $50 \mathrm{mg} / \mathrm{kg}$ group, the mtDNA contents were significantly decreased by $70 \%$ or higher in skeletal muscle, cardiac muscle, and liver $(P<0.01)$; the mtDNA content in kidney also significantly decreased $(P<0.05)$. However, in the metacavir $120 \mathrm{mg} / \mathrm{kg}$ group, the mtDNA contents significantly decreased, but they were all higher than those in AZT 50 $\mathrm{mg} / \mathrm{kg}$ group. Mitochondrial injury sufficient to cause injury to cells and clinical toxicity could require mtDNA reduction greater than $70 \%$, based on both in animal studies and HIV patients $^{[2,19,28,30]}$. These results suggested that AZT $50 \mathrm{mg} / \mathrm{kg}$ caused the decrease of mtDNA content, and the toxicity of metacavir is slight.

In metacavir $40 \mathrm{mg} / \mathrm{kg}$ group, after 3 months of dosing, the clinical toxic symptom only included slight fatty liver, and no other toxic injury was found. All the results indicating that doses below $40 \mathrm{mg} / \mathrm{kg}$ was safe. The above results also suggest that more attention should be paid on fatty degeneration of hepacytes and myopathies in the clinical trial phase.

On week 4 in the recovery phase, results showed that all these injuries were reversible after drug withdrawal, which showed that the drug should be given periodic. These results also suggest that metacavir has not a high risk for potential mitochondrial-related effects in humans.

In this experiment, it is a weakness that we did not probe into the effect of metacavir on mitochondrial DNA polymerase, which is the action target of metacavir. In future studies, the mechanism of the mitochondrial toxicity of metacavir should be further explored.

In conclusion, the mitochondrial toxicity of metacavir was mild in each tissue, and on week 4 in the recovery phase, results showed that all these injuries were reversible after drug withdrawal. These results suggest that metacavir has not a high risk for potential mitochondrial-related effects in rhesus monkeys and humans.

\section{Acknowledgements}

The research was supported by the Program for Changjiang Scholars and Innovative Research Team in University (IRT0853), the National and Sichuan Province Innovation Funds for moderate scale science and technology corporation (06C26215101716/06CX1607002), Sichuan Province Basic Research Program (2008JO0003/2008JY0100/2008JY0102), the youth Foundation of Sichuan Province Sci \& Tech Bureau, China (08ZQ026-061) and Program for Key Disciplines Construction of Sichuan Province (SZD0418).

\section{Author contribution}

Wen ZENG, Zheng-li CHEN and An-chun CHENG designed research; Wen ZENG and Yu-bo SUN performed research; An-chun CHENG, Zhan LI and Qi-hui LUO contributed new analytical tools and reagents; Qi-hui LUO and Feng-jun BI analyzed data; Wen ZENG and Zheng-li CHEN wrote the paper.

\section{References}

1 Janssen HL, van Zonneveld M, Schalm SW. Hepatitis B. N Engl J Med 2004; 350: 2719-20.

2 White AJ. Mitochondrial toxicity and HIV therapy. Sex Transm Infect 2001; 77: 158-73.

3 Kees Brinkman, Hadewych J M ter Hofstede. Mitochondrial toxicity of nucleoside analogue reverse trancriptase inhibitors: lactic acidosis, risk factors and therapeutic options. AIDS Rev 1999; 1: 140-6.

4 Birkus G, Hitchcock MJ, Cihlar T. Assessment of mitochondrial toxicity in human cells treated with tenofovir: comparison with other nucleoside reverse transcriptase inhibitors. Antimicrob Agents Chemother 2002; 46: 716-23.

5 Brinkman K, ter Hofstede HJ, Burger DM, Smeitink JA, Koopmans PP. Adverse effects of reverse transcriptase inhibitors: mitochondrial toxicity as common pathway. AIDS 1998; 12: 1735-44.

6 Carr A, Cooper DA. Adverse effects of antiretroviral therapy. Lancet 2000; 356: 1423-30.

7 John M, Nolan D, Mallal S. Antiretroviral therapy and the lipodystrophy syndrome. Antivir Ther 2001; 6: 9-20.

8 Moyle G. Clinical manifestations and management of antiretroviral 
nucleoside analog-related mitochondrial toxicity. Clin Ther 2000; 22: 911-36.

9 Lewis W, Copeland WC, Day BJ. Mitochondrial DNA depletion, oxidative stress, and mutation: mechanisms of dysfunction from nucleoside reverse transcriptase inhibitors. Lab Invest 2001; 81: 777-90.

10 Arnaudo E, Dalakas M, Shanske S, Moraes CT, DiMauro S, Schon EA. Depletion of muscle mitochondrial DNA in AIDS patients with zidovudine-induced myopathy. Lancet 1991; 337: 508-10.

11 Masanés F, Barrientos A, Cebrián M, Pedrol E, Miró O, Casademont $J$, et al. Clinical, histological and molecular reversibility of zidovudine myopathy. J Neurol Sci 1998; 159: 226-8.

12 Pezeshkpour G, Illa I, Dalakas MC. Ultrastructural characteristics and DNA immunocytochemistry in human immunodeficiency virus and zidovudine-associated myopathies. Hum Pathol 1991; 22: 1281-8.

13 Lewis W, Gonzalez B, Chomyn A, Papoian T. Zidovudine induces molecular, biochemical, and ultrastructural changes in rat skeletal muscle mitochondria. J Clin Invest 1992; 89: 1354-60.

14 Bissuel F, Bruneel F, Habersetzer F, Chassard D, Cotte L, Chevallier M, et al. Fulminant hepatitis with severe lactate acidosis in HIV-infected patients on didanosine therapy. J Intern Med 1994; 235: 367-71.

15 Dubinsky RM, Yarchoan R, Dalakas M, Broder S. Reversible axonal neuropathy from the treatment of AIDS and related disorders with 2,3dideoxycytidine (ddC). Muscle Nerve 1989; 12: 856-60.

16 Miller KD, Cameron M, Wood LV, Dalakas MC, Kovacs JA. Lactic acidosis and hepatic steatosis associated with use of stavudine: report of four cases. Ann Intern Med 2000; 133: 192-6.

17 Gerschenson M, Erhart SW, Paik CY, St Claire MC, Nagashima K, Skopets B, et al. Fetal mitochondrial heart and skeletal muscle damage in Erythrocebus patas monkeys exposed in Utero to 3-azido3-deoxythymidine. AIDS Res Hum Retroviruses 2000; 16: 635-44.

18 Li Z, Huang X, Jiang Z, Xiao Y, Liu C, Zhang L, et al. A sensitive and specific liquid chromatography-mass spectrometry method for determination of metacavir in rat plasma. J Chromatogr B Analyt Technol Biomed Life Sci 2008; 864: 9-14.

19 Biesecker G, Karimi S, Desjardins J, Meyer D, Abbott B, Bendele R, et al. Evaluation of mitochondrial DNA content and enzyme levels in tenofovir DF-treated rats, rhesus monkeys and woodchucks. Antiviral Research 2003; 58: 217-25.

20 Walker UA, Setzer B, Venhoff N. Increased long-term mitochondrial toxicity in combinations of nucleoside analogue reverse-transcriptase inhibitors. AIDS 2002; 16: 2165-73.

21 Richardson FC, Tennant BC, Meyer DJ, Richardson KA, Mann PC, McGinty GR, et al. An evaluation of the toxicities of 2'-fluorouridine and 2'-fluorocytidine- $\mathrm{HCl}$ in F344 rats and woodchucks (Marmota monax). Toxicol Pathol 1999; 27: 607-17.

22 Tennant BC, Baldwin BH, Graham LA, Ascenzi MA, Hornbuckle WE, Rowland $\mathrm{PH}$, et al. Antiviral activity and toxicity of fialuridine in the woodchuck model of hepatitis B virus infection. Hepatology 1998: 28: 179-91.

23 Bishop JB, Tani Y, Witt K, Johnson JA, Peddada S, Dunnick J, et al. Mitochondrial damage revealed by morphometric and semiquantitative analysis of mouse pup cardiomyocytes following in utero and postnatal exposure to zidovudine and lamivudine. Toxicological sciences 2004; 81: 512-7.

24 Chan SS, Santos JH, Meyer JN, Mandavilli BS, Cook DL Jr, McCash CL, et al. Mitochondrial toxicity in hearts of CD-1 mice following perinatal exposure to AZT, 3TC, or AZT/3TC in combination. Environmental and molecular mutagenesis 2007; 48: 190-200.

25 Mazzucco CE, Hamatake RK, Colonno RJ, Tenney DJ. Entecavir for treatment of hepatitis $\mathrm{B}$ virus displays no in vitro mitochondrial toxicity or DNA polymerase gamma inhibition. Antimicrob Agents Chemother 2008; 52: 598-605.

26 Kakuda TN. Pharmacology of nucleoside and nucleotide reverse transcriptase inhibitor-induced mitochondrial toxicity. Clin Ther 2000; 22: 685-708.

27 Martin JL, Brown CE, Matthews-Davis N, Reardon JE. Effects of antiviral nucleoside analogs on human DNA polymerases and mitochondrial DNA synthesis. Antimicrob Agents Chemother 1994; 38 : 2743-9.

28 Côté HC, Brumme ZL, Craib KJ, Alexander CS, Wynhoven B, Ting L, et al. Changes in mitochondrial DNA as a marker of nucleoside toxicity in HIV-infected patients. N Engl J Med 2002; 346: 811-20.

29 Blanche S, Tardieu M, Rustin P, Slama A, Barret B, Firtion G, et al. Persistent mitochondrial dysfunction and perinatal exposure to antiretroviral nucleoside analogues. Lancet 1999; 354: 1084-9.

30 Morton DM. Importance of species selection in drug toxicity testing. Toxicol Lett 1998; 102-103: 545-50. 